\title{
The Use of Support Systems by Informal Caregivers:
}

\section{An Australian Experience}

Nerina Vecchio

Qualifications: BA, Bec, Mecon, PhD

Griffith University, Business School 


\begin{abstract}
Based on the data collected from the Australian Survey of Disability, Ageing and Carers in 2003, this study investigated the factors that influenced the assistance received by primary caregivers of non-institutionalised individual's aged 15 years and over with either profound or severe disabilities. An understanding of caregivers and their use of support systems will assist policy makers in implementing strategies that ensure the viability of the community care programs by meeting the demands within the health sector as demographics change over time.
\end{abstract}

This study found that the majority of primary caregivers (61\%) did not receive any main source of assistance. The results from the multinominal regression revealed that caregivers less likely to receive any main source of assistance included those that were spouses of recipients, younger in age, did not participate in the labour force and resided in the remote regions of Australia. Individuals caring for older aged recipients or recipients that possessed a severe rather than profound disability were also less likely to receive any main source of assistance. Caregivers of recipients with either a physical or mental main disabling condition tended to seek informal and formal assistance, respectively. It is interesting to note that after controlling for other variables the gender of the caregiver did not impact on the type of assistance received.

Key words: Primary caregivers, Informal support, Formal support, Assistance, Profound and severe disabilities. 


\section{Introduction}

Support systems, both formal (e.g. respite) and informal (e.g. unpaid support by family and friends) assist primary caregivers in maintaining consistent and adequate care. Based on the data collected from the Australian Survey of Disability, Ageing and Carers (ABS 2003c) this study identified the variables that influenced the type of assistance received by primary caregivers of the non-institutionalised recipients of care aged 15 years and older. Recipients with either profound or severe disabilities were chosen for the analysis since they require and receive the greatest amount of care (AlHW 2004). Specifically this study evaluated the association between several characteristics - family composition, caregiver and recipient characteristics - and the likelihood of primary caregivers receiving assistance.

The anticipated rise in the demand for home care services associated with an aging Australian population is compounded by rising childlessness, declining family size, shifts in perceptions of family obligation, rising divorce rates and rising female employment rates (AlHW 2004 p38). To maintain the viability of the community care program of which informal caregivers are a central component an investigation of the use of support systems by caregivers is imperative.

\section{Literature Review}

Recognition of the critical role of primary caregivers in the health care sector and concerns of the care arrangements of an aging population has led to increased research into primary care. While informal caregivers provide the major part of support to those who need assistance to remain living at home (AlHW 2003), few use any formal services (Fine and Thomson, 1997). Brodaty, Thomson, Thompson and Fine's comprehensive review of 
the literature regarding service non-use by caregivers of people with dementia found that the Australian research reflected international themes (refer Brodaty et al 2005). Within the Australian context the reasons for the limited use of services among informal caregivers included: caregivers were managing at the moment; service characteristics; lack of awareness of the services available; cultural and ethnic influences. Brodaty and colleague's (2005) own investigation of a sample of informal caregivers of people with dementia residing in the State of Victoria, Australia, revealed low service useage despite considerable proportions of caregivers reporting low levels of life satisfaction and high levels of burden and resentment. Consistent with other Australian studies they found that caregivers did not use formal services because they either did not need these services, the care recipient was reluctant to use these services or a general lack of knowledge of the services available (Brodaty et al 2005).

Other studies have focused on the choice of mix between formal and informal services. The Australian Institute of Health and Welfare (AIHW) (2004) noted that care recipients with primary carers were likely to be less reliant on non-professional formal assistance. In contrast, those without a primary carer were more likely to use professional services at a higher rate. Edelbrock's (et al 2003) investigation of older people residing in Sydney also found a compensatory relationship between professional community services and informal services. Those without informal care made greater use of formal services. Jette's (1995) study found that this degree of substitution and supplementation between formal and informal services depended on the underlying care continuum - from informal care to mixed informal and formal and finally to full formal care. 
Studies that focus on the use of support services by primary caregivers are often confined to the investigation of caregivers of either older people (Weiss et al 2005; Edelbrock et al 2003; Stoddart et al 2002; Broe et al 2002) or recipients with a particular disabling condition (Woolfe et al 2007; Brodaty et al 2005; Foster et al 2005; Spruytte et al 2002). Many studies also rely on the data sourced from regional rather than national surveys. The saturation of the literature on specific groups of caregivers needs to be balanced by research that provides insight into the general caregiver population. Such investigations allow findings to be generally applied for policy purposes.

\section{Research Questions}

The aim of the study reported here is to identify carer and recipient characteristics that influence the type of assistance received by primary caregivers. Since the analysis is based on a national survey the findings will assist policy makers in the development of effective community based support for caregivers and their families.

Specifically the questions posed in this study are:

1. What type of assistance do primary caregivers utilise? They may utilise either: no main source of assistance; assistance mainly from informal sources or; assistance mainly from formal sources.

2. What individual carer and recipient characteristics predict the type of assistance utilised by primary carers?

Several terms used in this paper are clarified in Box 1 . The definitions are based on the ABS survey (ABS 2003b). It is an assumption of this study that caregivers as a whole 
possess similar information or lack of information regarding the availability of support services.

\section{The Method}

The Sample

This study was based on the data from the Australian Survey of Disability, Ageing and Carers (SDAC), Confidential Unit Record Files (CURF) (ABS 2003c). The survey, conducted throughout Australia in the months of June to November 2003, covered people in both urban and rural areas in all states and territories. Every member of the selected households was included in the survey irrespective of disability status, age and carerstatus (ABS 2003a p56). Trained interviewers from the Australian Bureau of Statistics (ABS) collected the household component of the data survey from a sample of 36088 persons (ABS 2003a).

For weighting purposes, the 2003 SDAC was benchmarked to the estimated population at 30 June 2003, based on results from the 2001 Census of Population and Housing. A subsample of 526 persons from the national sample comprised the non-institutionalised main recipients of care with either profound or severe disabilities, aged 15 and over and their caregivers. The ABS supplied the weightings (person weights) in the SDAC CURF dataset to represent the Australian population that met the study's criteria, resulting in the selected estimated population of $274,987$.

\section{The Model}

Previous studies that have used regression analysis to investigate the circumstances of primary carers have typically included gender, age, family relationships, disability type, 
race and income in the model (Stoddart, Whitley, Harvey and Sharp, 2002; Spruytte et al 2002). Others have also included the level of disability (Edelbrock et al 2003; Vecchio 2007; Broe et al 2002), location (Weiss, Gonzalez, Kabeto and Langa 2005) and the duration of care (Jette 1995). Due to the large amount of missing cases (9.9\%) found in the income variable, in this study labour force status became a proxy for individual income (highly correlated with receipt of government pension at $0.670, p<0.01$ ).

The model also included the variable 'perceived need for assistance' as a binary variable: needs met; needs unmet. 'Need' refered to the non-financial support provided to the primary carer (ABS 2003b p71). Such assistance included one or more of the following activities: cognition or emotion, communication, health care, housework, meal preparation, mobility, paperwork, property maintenance, self-care, transport (ABS 2003b p71). It is acknowledged that perceived need does not equate to actual need. Nevertheless, this indicator comes closest to providing information on the non-financial support required by primary caregivers. Any further reference to 'need' refers to the primary carer's perceived need for assistance.

\section{INSERT TABLE 1 HERE}

The model consisted of the type of assistance received by the carer as the dependent variable, the explanatory variables and the control variables defined in Table 1 . The model became: 
Type of assistance $_{j}=\beta_{0}+\beta_{1}$ Sex of recipient S $_{i}+\beta_{2}$ Age of recipient $_{i}+\beta_{3}$ Disabling

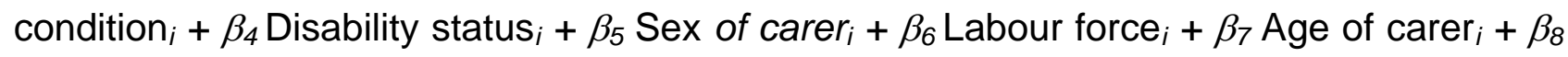
Relation $_{i}+\beta_{9}$ Need $_{i}+\beta_{10}$ Duration of care $i+\beta_{11}$ COB $_{i}+\beta_{12}$ Region $_{i}+\varepsilon_{j}$

The multinominal logistic model estimated the probability of the type of assistance received by the caregiver. Specifically, a link was determined between the assistance type and several characteristics. The regression allowed the analysis of the three categories for the dependent variable: no assistance 60.7\%; informal assistance, 29.8\%; and formal assistance, 9.5\%. 'No assistance', became the reference category to which the other two variables were compared.

\section{Results}

In this section, the descriptive statistics relating to the profile of caregivers and their recipients are presented followed by the results of the regression analysis.

\section{Profile of Main Recipients of Care}

Table 2 presents the characteristics of the recipients with either profound $(60.7 \%)$ or severe (39.3\%) disabilities. The majority possess a physical (85.8\%) rather than a mental (14.2\%) main disabling condition.

\section{INSERT TABLE TWO HERE}

In reference to the main disabling condition, $62.6 \%$ of caregivers of those with a physical condition receive no main source of assistance in their role as carer compared to $48.9 \%$ of caregivers of those with a mental condition. Since those with a mental disabling condition 
are also likely to possess physical disabilities this may explain the greater proportion of caregivers within this group that receive assistance.

The findings relating to gender reflect the aging of Australia's population. Here a greater proportion of caregivers of male recipients receive no main source of assistance (64.3\%) compared to caregivers of female recipients (57.3\%). Research shows that older men tend to be cared for by their spouse. Older women often outlive their husbands and so rely on care outside the home (Vecchio and Jackson 2002).

\section{Profile of Caregivers}

Overall the majority of caregivers (80.9\%) report that they receive adequate assistance. Of these caregivers, $65 \%$ report no main source of assistance. Of those that do require further assistance (19.1\%), more than two out of five do not receive any main source of assistance.

The greater proportion of male caregivers (65.3\%) that report no main source of assistance compared to female caregivers (58.1\%) possibly reflects the weaker social networks of males. It is well documented in the literature that older men possess weaker social networks (Vecchio et al 2001; Hessler et al 1995; Avlund, Damsgaard and Holstein 1998; Millward 1998 1999). The smaller proportion of male caregivers receiving informal assistance compared to females (25.8\% and $32.1 \%$ respectively) supports the findings of previous research. Another explanation for the lesser support received by male caregivers is that male caregivers may be looking after spouses who are not as severely disabled and do not require as much assistance. Also, male caregivers may be physically stronger than female caregivers and better able to lift and assist in mobilising activities than female 
caregivers. Consequently female caregivers may require more assistance than male caregivers.

Location does appear to impact on the type of assistance received by the carer. For instance the proportion of carer's with no main source of assistance increases with the remoteness of the area, from $57.3 \%$ in major cities, to $62.9 \%$ in inner regional, and to $72.4 \%$ in outer regions. While lower levels of informal assistance is reported by those residing in outer regions, similar levels of formal assistance is reported by caregivers residing in the three location categories (between 9.3 and 9.6\%). Based on the findings of the descriptive statistics the shortfall in assistance in the outer regions of Australia appears to arise from inadequate family support. In the next sub-section this finding will be verified using regression analysis.

Cultural influences are evident in the type of support received. Caregivers from nonEnglish speaking countries typically receive greater assistance from family and friends (38\%) in their caring role compared to others (Australians 30\%, Main English speaking countries 12.8\%). In contrast, caregivers born in English speaking countries outside Australia report the lowest level of assistance and a greater use of formal services. Although the patterns and timing of migration may explain some of the variation, this was not captured in the dataset.

Of all the carer relationships, spouses who care for their partners receive the least assistance (74.2\% receive no main source of assistance). In stark contrast, parents (51.5\%), adult children (50.1\%) or other relatives (44.4\%) rely more heavily on family and friends. The phenomena may again reflect the older age cohorts of spouses who are 
caregivers. It is suspected that caregivers who are spouses are either semi or fully retired from the workforce and so less reliant on others for support. The reverse is true for caregivers who are parents, adult children and other family/friends as they must often juggle work and family commitments. Also spouses may be more willing to perform personal care tasks for their partner. In contrast, adult children and other family and friends may be reluctant to perform personal care duties.

\section{INSERT TABLE THREE HERE}

Referring to the duration of care variable, during the first 12 months of a disability, as households come to terms with the recipient's illness and care demands, little assistance is received from either formal or informal sources. Indeed, during the initial year of care $77.5 \%$ of these caregivers receive no main source of assistance.

\section{Regression Analysis}

Influences among and between the characteristics of caregivers and their recipients may distort the findings in the descriptive statistics and mislead the researcher. For instance, although a greater proportion of male caregivers receive no main source of assistance compared to female caregivers this may occur because of the family relationship, age or lower labour force participation rate of these caregivers rather than because of gender per se. In this section the regression analysis controls for confounding variables.

The model resulted in a Nagelkerke $\mathrm{R}^{2}$ of $25 \%$. This means that the independent variables of the model explained $25 \%$ of the variance in the type of assistance received by primary carers. The likelihood ratio tested the contribution of the individual predictors to the model 
by comparing the model with and without each predictor. The variables that contributed to the model, in descending order from most to least, included: relationship, country of birth, age of carer, labour force status, perceived need of assistance, age of main recipient, region, disability status of main recipient, duration of care and disabling condition of recipient. The gender of either the carer or the recipient contributed little to the model.

Table 4 presents the results from the multinominal regression analysis. Parameters with significant negative coefficients decrease the likelihood of that response category with respect to the reference category, 'no main source of assistance'. Parameters with positive coefficients increase the likelihood of that response category (SPSS 2006). To verify the interpretation of the results in the nominal regression, two separate binary logistic regressions (not reported here) were also run.

\section{INSERT TABLE FOUR HERE}

The interpretation of the results of Table 4 are summarised and presented in Table 5. Referring to the 'informal' column in Table 5, there is an increased likelihood of receiving informal assistance when caregivers are either born in non-English speaking countries, participate in part time employment or whose recipients possess a physical main disabling condition with respect to the reference category.

Those more likely to receive formal assistance include caregivers who are born in English speaking countries including Australia participate in the laborforce and whose recipients possess a profound disability and a mental rather than physical main disabling condition. 


\section{INSERT TABLE FIVE HERE}

Caregivers other than spouses, those who perceive their needs as unmet, report less duration of care, reside in either a major city or inner region have an increased probability of receiving assistance, either informal or formal, compared to the reference category. With each successively older 5 year age group starting at 15-19 years the odds ratio of receiving informal or formal care decreases among recipients but increases among primary carers compared to the reference category 'no main source of assistance'. Caregivers of those with profound disabilities are more likely to belong to either the 'informal' or formal category. It is interesting to note that after controlling for the other variables the gender of the caregiver does not impact on the type of assistance received.

\section{Limitations}

The limitations of this study included data restrictions that did not allow the inclusion of some relevant independent variables into the model. The disability variables used in the model were based on the main disabling condition rather than all the diagnosed conditions of the recipient. Also, for the selected sample the available data did not provide adequate information on family members or caregivers other than primary caregivers. The lack of data relating to the carer's knowledge of available services is another limitation. Finally, the study is concerned with the broad type of assistance utilised by carers, rather than what is available and not accessed. Future analysis of these data would add to the literature. 


\section{Discussion and Conclusion}

While the inadequacy of assistance reported by some caregivers (19.1\%) cannot be ignored, it needs to be recognized that most caregivers (80.9\%) believed that their assistance was adequate. Of the selected population of primary caregivers, the majority, $60.7 \%$, received no main source of assistance. This compared to $29.8 \%$ of caregivers who received informal assistance and $9.5 \%$ who received formal assistance as their main source of support.

Furthermore, the majority of caregivers who did not receive any main source of assistance did not require further assistance from either formal or informal sources. It is speculated here that caregivers perceived themselves as best able to interpret and meet the highly individualised needs of their recipients. Indeed, when asked what factors affected an individual's decision to assume the role of carer, $42.5 \%$ of the total selected estimated population answered that they could provide better care than others (based on further analysis of the ABS 2003 CURF SDAC).

The decision to receive no assistance was primarily driven by social and cultural factors reflected in family relationships. This finding, reported in the descriptive statistics, was verified in the regression analysis that controlled for confounding variables.

Among the selected caregiver population, those less likely to receive assistance included spouses of recipients, younger aged caregivers, and those that did not participate in the labour force. The current skills shortage in the Australian labour market and recent efforts by the Federal government to encourage older workers to delay retirement (e.g. changes in the superannuation in 2006) may increase the demand for formal support services as 
less of this group become available to provide care. The increased flexibility of the Australian workforce, however, may alleviate to some extent future demand for formal services as workers combine care duties with flexible work arrangements.

Households residing in the outer regions of Australia received the least assistance compared to those residing in cities or inner regions. It is interesting to note similar proportions of caregivers receiving formal services. This suggests that the inadequate level of support in rural Australia arises from the lack of extended family and friends residing nearby. In contrast, caregivers from non-English speaking backgrounds received the greatest amount of informal support, possibly reflecting their close community ties.

When controlling for other variables, it was found that gender contributed little in explaining the types of support services received by primary carers. Although the descriptive statistics revealed that compared to their female counterparts, a greater proportion of male caregivers and recipients received the least amount of assistance, the results from the regression revealed that factors other than gender explained the differential.

Expected shortfalls in the availability of primary caregivers as a result of changing demographics highlight the need to direct future research towards the investigation of support service utilisation. Such an investigation will better equip policy makers in ensuring the sustainability of community care programs as the demands of an ageing population rise to unprecedented levels. 


\section{References}

Australian Bureau of Statistics (2003a) Survey of disability, ageing and carers, users guide CURF. Catalogue number 4430.0. Canberra: Australian Bureau of Statistics.

Australian Bureau of Statistics (2003b) Disability, ageing and carers: Summary of Findings. Canberra: Australian Bureau of Statistics.

Australian Bureau of Statistics (2003c) Survey of disability, ageing and carers, Confidential Unit Record Files. Canberra: Australian Bureau of Statistics.

Australian Institute of Health and Welfare (2003) Informal Care, Australia's Welfare 2003. AusInfo, 65-120. Canberra: AlHW.

Australian Institute of Health and Welfare (2004) Cares in Australia. Assisting frail older people and people with a disability. Aged Care Series No. 8. Canberra: AlHW.

Avlund K., Damsgaard M. \& Holstein, B. (1998) Social relations and mortality. An eleven year follow up study of 70 year old men and women in Denmark. Social Science and Medicine, 47 (5), 635-643.

Brodaty H., Thomson C., Thompson C. \& Fine M. (2005) Why caregivers of people with dementia and memory loss don't use services. International Journal of Geriatric Psychiatry, 20, 537-546.

Broe G., Grayson D., Waite L., Creasey H., Edelbrock D., Bennett H. \& Brooks W. (2002) Determinants of service use among the elderly: the Sydney older persons study. Australasian Journal on Ageing, 21 (2), 61-66.

Edelbrock D., Waite L., Broe G., Grayson D. \& Creasey H. (2003) The Relation Between Unpaid Support and the Use of Formal Health Services: the Sydney Older Persons Study. Australasian Journal on Ageing, 22 (1), 2-8.

Fine M. \& Thomson C. (1997) Beyond caring: Informal care and the use of community support services by Home and Community Care Clients. In Sociology of Aging: International Perspectives, Minichiello V, Chappell N, Kendig H, Walker A (eds). Melbourne: International Sociological Association.

Hessler R., Jia S., Madsen R. \& Pazaki H. (1995) Gender, social networks and survival time: A twenty year study of the rural elderly. Archives of Gerontology and Geriatrics, 21, 291-306.

Jette A., Tennstedt S. \& Crawford S. (1995). How does formal and informal community care affect nursing home use? Journal of Gerontology, 50B(1), S4-S12.

McCann S., \& Evans D. (2002) Informal care: the views of people receiving care. Health and Social Care in the Community, 10 (4), 221-228. 
Millward C. (1998) Family relationships in intergenerational exchange in later life, Working Paper No 15, Australian Institute of Family Studies.

Millward C. (1999) Understanding links between family experience, obligations and expectations in later life. Working paper 19, Australian Institute of Family Studies.

Spruytte N., Van Audenhove C., Lammertyn F. \& Storms G. (2002) The quality of the caregiving relationship in informal care for older adults with dementia and chronic psychiatric patients. Psychology and Psychotherapy: Theory, Research and Practice, 75, 295-311.

Stoddart H., Whitley E., Harvey I. \& Sharp D. (2002) What determines the use of home care services by elderly people? Health and Social Care in the Community, 10 (5), 348-360.

Vecchio, N., Jackson, S. \& Guest, R. (2001). Determinants of Socioeconomic Status of the Aged on Queensland's Gold Coast. Does Gender Matter? Economic Papers, September issue, 43-58.

Vecchio, N. \& Jackson, S. (2002). Home and Community Care and the Principle of Self-reliance: Implications for Older Australians. Australian Journal of Regional Studies, 8 (2), 183-199.

Vecchio N. (2007) Labour market decisions of Australian families coping with mental and physical disabilities. Economic Analysis and Policy, 37 (1), 61-75.

Weiss C., Gonzalez H., Kabeto M. \& Langa K. (2005) Differences in amount of informal care received by non-Hispanic whites and Latinos in a nationally representative sample of older Americans. Journal of the American Geriatrics Society, 53 (1), 146-152.

Correspondence:

Dr Nerina Vecchio

Griffith Business School

Griffith University Gold Coast Campus

PMB 50 Gold Coast Mail Centre Queensland 9726 Australia

Email: n.vecchio@griffith.edu.au

Telephone: 0755588284 


\section{Box 1: Definitions}

Informal carer: Family or friends who provide unpaid care and support to care recipients.

Primary carer: A carer who is aged 15 years or over and provides the most assistance to the care recipient. The assistance is ongoing for at least six months and includes communication, mobility and self care. In this paper any further reference to carer refers to the informal primary carer.

Care recipient: A non-institutionalised person aged 15 and over with either a profound or severe disability.

Disability: A limitation, restriction or impairment that lasts at least 6 months and restricts everyday activities.

Profound disability: An inability to do or always need help with a core activity task in communication, mobility and self-care.

Severe disability: Sometimes need help with a core-activity task, has difficulty understanding or being understood by family or friends, can communicate more easily using sign language or non-spoken forms of communication.

Mental Disability: Mental and behavioural disorders including psychoses and mood effective disorders (Dementia, Alzheimer's, depression and mood effective disorders), neurotic, stress-related and somatoform disorders (nervous tension, stress), intellectual and developmental disorders (Down syndrome) and other mental and behavioural disorders.

The three main sources of assistance received by the primary caregivers: These are measured not by the assistance specifically directed towards the carer but the help directed towards the disabled person they care for. Assistance does not include professional health services that a person with a disability may receive.

1. Formal: Help provided to persons with disabilities by (a) organisations or individuals representing organisations, or (b) other persons who provide assistance, on a regular, paid basis and who are not associated with any organisation.

2. Informal: Unpaid help or supervision that is provided to persons with disabilities or persons aged 60 years and over living in households. It includes only assistance that is provided for one or more of the specified tasks comprising an activity because of a person's disability or age. Informal assistance may be provided by family, friends or neighbours.

3. No main source of assistance. A carer provides the majority of care and receives little reliable assistance or no assistance either from informal or formal sources. 
Table 1: Dependent and independent variables

\begin{tabular}{|c|c|}
\hline Variable & Definition \\
\hline $\begin{array}{l}\text { Type of } \\
\text { assistance }\end{array}$ & $\begin{array}{l}\text { Type of assistance received by the primary carer: } 1 \text { if no main source of assistance } \\
\text { (reference category); } 2 \text { if assistance mainly from informal sources; } 3 \text { if assistance } \\
\text { mainly from formal sources. }\end{array}$ \\
\hline Sex of recipient & Sex of main recipient of care: 1 if male, 0 if female. \\
\hline Age of recipient & $\begin{array}{l}\text { Age of main recipient of care: ordinal age group from } 15 \text { years in } 5 \text { year intervals } \\
\text { up to } 85 \text { and over, treated as a continuous variable }(4=15-19,5=20-25, \ldots .18=85 \\
\text { and over) }\end{array}$ \\
\hline $\begin{array}{l}\text { Disabling } \\
\text { condition }\end{array}$ & Main disabling condition of recipient of care: 1 if mental, 0 if physical. \\
\hline Disability status & Disability status of main recipient of care: 1 if profound, 0 if severe. \\
\hline Sex of carer & Gender of primary carer: 1 if male, 0 if female \\
\hline Labour force & $\begin{array}{l}\text { Labour force status of primary carer: } 1 \text { if full time, } 2 \text { if part time, } 3 \text { if not in the } \\
\text { labour force (reference category). }\end{array}$ \\
\hline Age of carer & $\begin{array}{l}\text { Age of primary carer: ordinal age-group from } 15 \text { years in } 5 \text { year intervals until } 85 \\
\text { and over treated as a continuous variable }(4=15-19,5=20-25, \ldots ., 18=85 \text { and over) }\end{array}$ \\
\hline Relation & $\begin{array}{l}\text { Relationship of primary carer to main recipient of care: spouse (reference } \\
\text { category), parent, offspring, friend/neighbour/other relative. }\end{array}$ \\
\hline Need & Perceived need of assistance in caring role: 1 if unmet need, 0 if needs met. \\
\hline Duration of care & $\begin{array}{l}\text { Duration of care: ordinal group from less than } 1 \text { year in } 5 \text { year intervals until } 35 \text { and } \\
\text { over treated as a continuous variable }(2=\text { less than } 1 \text { year, } 3=1-4,4=5-9, \ldots \ldots \text {, } \\
10=35 \text { and over })\end{array}$ \\
\hline $\mathrm{COB}$ & $\begin{array}{l}\text { Country of Birth: } 1 \text { if Australia, } 2 \text { if main English speaking country, } 3 \text { if non-English } \\
\text { speaking country (reference category). }\end{array}$ \\
\hline Region & Region of residence: 1 if major city, 2 if regional, 3 if remote (reference category). \\
\hline
\end{tabular}


Table 2: Characteristics of recipients of care with profound and severe disabilities, aged 15 years and over, Australia, 2003 (weighted data).

\begin{tabular}{|c|c|c|c|c|c|}
\hline \multirow[t]{2}{*}{ Category } & & \multicolumn{4}{|c|}{$\begin{array}{l}\text { Relationship of main source of assistance } \\
\text { to primary carer }\end{array}$} \\
\hline & & $\begin{array}{c}\text { No } \\
\text { source }\end{array}$ & Informal & Formal & $\begin{array}{c}\text { Total } \\
(\mathrm{N}=274987)\end{array}$ \\
\hline & & Row \% & Row \% & Row \% & Category \% \\
\hline \multirow[t]{2}{*}{ Disability status } & $\begin{array}{l}\text { Severe } \\
(N=108162)\end{array}$ & 70.2 & 23.5 & 6.2 & 39.3 \\
\hline & $\begin{array}{l}\text { Profound } \\
(\mathrm{N}=166824)\end{array}$ & 54.5 & 33.9 & 11.7 & 60.7 \\
\hline \multirow[t]{2}{*}{ Disabling Condition } & $\begin{array}{l}\text { Physical } \\
(\mathrm{N}=235990)\end{array}$ & 62.6 & 28.7 & 8.7 & 85.8 \\
\hline & $\begin{array}{l}\text { Mental } \\
(\mathrm{N}=38997)\end{array}$ & 48.9 & 36.6 & 14.4 & 14.2 \\
\hline \multirow[t]{2}{*}{ Sex } & $\begin{array}{l}\text { Female } \\
(\mathrm{N}=144470)\end{array}$ & 57.3 & 32.8 & 9.9 & 52.5 \\
\hline & Male $(\mathrm{N}=130517)$ & 64.3 & 26.5 & 9.1 & 47.5 \\
\hline TOTAL & 274986 & 60.7 & 29.8 & 9.5 & 100 \\
\hline
\end{tabular}


Table 3: Caregivers of non-institutionalised recipients of care with profound and severe disabilities, Australia, 2003 (weighted data).

\begin{tabular}{|c|c|c|c|c|c|c|}
\hline \multirow[t]{3}{*}{ Category } & & & \multicolumn{4}{|c|}{$\begin{array}{l}\text { Relationship of main source of } \\
\text { assistance to primary carer }\end{array}$} \\
\hline & & \multirow[b]{2}{*}{$N$} & $\begin{array}{c}\text { No } \\
\text { source }\end{array}$ & Informal & Formal & Total \\
\hline & & & Row \% & Row \% & Row \% & $\begin{array}{c}\text { Category } \\
\%\end{array}$ \\
\hline \multirow[t]{2}{*}{ Need } & Adequate assistance & 222417 & 65.0 & 26.0 & 9.0 & 80.9 \\
\hline & Needs assistance & 52570 & 42.3 & 46.1 & 11.7 & 19.1 \\
\hline \multirow[t]{2}{*}{ Sex } & Female & 176244 & 58.1 & 32.1 & 9.8 & 64.1 \\
\hline & Male & 98743 & 65.3 & 25.8 & 9.0 & 35.9 \\
\hline \multirow[t]{3}{*}{ Region } & Major cities & 167957 & 57.3 & 33.1 & 9.6 & 61.1 \\
\hline & Inner regional & 67848 & 62.9 & 27.7 & 9.4 & 24.7 \\
\hline & Other areas & 38645 & 72.4 & 18.3 & 9.3 & 14.3 \\
\hline \multirow[t]{3}{*}{ Country of Birth } & Australia & 190590 & 60.2 & 30.1 & 9.7 & 69.3 \\
\hline & $\begin{array}{l}\text { Main English } \\
\text { speaking }\end{array}$ & 29646 & 72.6 & 12.7 & 14.8 & 10.8 \\
\hline & Other countries & 54751 & 55.9 & 38.0 & 6.1 & 19.9 \\
\hline \multirow{4}{*}{$\begin{array}{l}\text { Relationship of primary } \\
\text { carer to main recipient }\end{array}$} & Spouse/partner & 169730 & 74.2 & 17.6 & 8.2 & 61.7 \\
\hline & Father or mother & 32153 & 32.7 & 51.5 & 15.8 & 11.7 \\
\hline & Son or daughter & 54325 & 40.2 & 50.1 & 9.8 & 19.8 \\
\hline & Other relative, friend & 18778 & 45.2 & 44.4 & 10.3 & 6.8 \\
\hline \multirow[t]{3}{*}{ Labour force } & Employed full-time & 44293 & 46.2 & 42.7 & 11.1 & 16.1 \\
\hline & Employed part-time & 36874 & 57.9 & 30.4 & 11.6 & 13.4 \\
\hline & Not in labour force & 191671 & 64.1 & 27.0 & 8.9 & 70.5 \\
\hline \multirow[t]{7}{*}{ Duration of care } & Less than one year & 11172 & 77.5 & 15.2 & 7.2 & 4.2 \\
\hline & 1-4 years & 95381 & 54.3 & 35.5 & 10.1 & 35.6 \\
\hline & $5-9$ years & 68892 & 66.9 & 23.0 & 10.1 & 25.7 \\
\hline & 10-14 years & 32248 & 76.6 & 15.1 & 8.3 & 12.0 \\
\hline & $15-19$ years & 24803 & 52.9 & 34.5 & 12.6 & 9.3 \\
\hline & $20-29$ years & 20238 & 59.9 & 32.2 & 7.9 & 7.6 \\
\hline & 30 years or more & 15266 & 36.4 & 54.8 & 8.9 & 5.7 \\
\hline TOTAL & & 274986 & 60.7 & 29.8 & 9.5 & 100 \\
\hline
\end{tabular}


Table 4. Relationship between the main source of assistance and carer/recipient characteristics - 'no main source of assistance' is the reference category

\begin{tabular}{|c|c|c|c|c|c|c|c|c|c|c|}
\hline & \multicolumn{5}{|c|}{ Informal } & \multicolumn{5}{|c|}{ Formal } \\
\hline & B & $\begin{array}{l}\text { Std. } \\
\text { Error }\end{array}$ & $\begin{array}{l}\text { Odds } \\
\text { Ratio }\end{array}$ & $\begin{array}{c}95 \% \\
\text { Inter } \\
\text { Odds }\end{array}$ & $\begin{array}{l}\text { Conf } \\
\text { al for } \\
\text { Ratio }\end{array}$ & B & $\begin{array}{l}\text { Std. } \\
\text { Error }\end{array}$ & $\begin{array}{l}\text { Odds } \\
\text { Ratio }\end{array}$ & $\begin{array}{r}95 \% \\
\text { Inter } \\
\text { Odds }\end{array}$ & $\begin{array}{l}\text { Conf } \\
\text { al for } \\
\text { Ratio }\end{array}$ \\
\hline Disabling Condition & -.308 & .015 & $.735^{\star}$ & .713 & .757 & .386 & .021 & $1.472^{*}$ & 1.412 & 1.533 \\
\hline Need & .667 & .012 & $1.949^{\star}$ & 1.902 & 1.996 & .256 & .018 & $1.292^{*}$ & 1.247 & 1.338 \\
\hline Disability status & .208 & .011 & $1.232^{\star}$ & 1.205 & 1.259 & .653 & .017 & $1.921^{*}$ & 1.859 & 1.984 \\
\hline Age of carer & .017 & .003 & $1.017^{*}$ & 1.012 & 1.022 & .288 & .004 & $1.334^{*}$ & 1.323 & 1.346 \\
\hline Age of recipient & -.065 & .002 & $.937^{*}$ & .933 & .941 & -.140 & .004 & $.869 *$ & .863 & .875 \\
\hline Sex of carer & -.017 & .013 & .983 & .959 & 1.009 & .029 & .021 & 1.029 & .988 & 1.072 \\
\hline Sex of recipient & .017 & .013 & 1.017 & .992 & 1.044 & .335 & .021 & $1.398^{*}$ & 1.340 & 1.458 \\
\hline Duration of care & -.024 & .003 & $.977^{\star}$ & .970 & .983 & -.162 & .005 & $.850^{*}$ & .842 & .859 \\
\hline Relation Other ${ }^{a}$ & 1.355 & .019 & $3.876^{*}$ & 3.735 & 4.021 & .824 & .031 & $2.279^{\star}$ & 2.146 & 2.421 \\
\hline Relation SonDau ${ }^{a}$ & 1.567 & .019 & $4.791^{*}$ & 4.619 & 4.968 & 1.740 & .031 & $5.695^{\star}$ & 5.361 & 6.049 \\
\hline Relation Parent $^{a}$ & 1.673 & .021 & $5.326^{*}$ & 5.106 & 5.555 & 1.002 & .032 & $2.723^{*}$ & 2.555 & 2.901 \\
\hline Region City ${ }^{b}$ & .649 & .016 & $1.914^{*}$ & 1.855 & 1.976 & .345 & .021 & $1.412^{*}$ & 1.355 & 1.472 \\
\hline Region Regional $^{\mathrm{b}}$ & .597 & .018 & $1.816^{*}$ & 1.754 & 1.881 & .384 & .024 & $1.468^{\star}$ & 1.401 & 1.538 \\
\hline Labour force F/Time $^{c}$ & .475 & .015 & $1.608^{*}$ & 1.562 & 1.654 & 1.021 & .023 & $2.777^{*}$ & 2.655 & 2.906 \\
\hline Labour force P/Time $^{\mathrm{C}}$ & -.396 & .016 & $.673^{*}$ & .652 & .695 & .358 & .023 & $1.431^{*}$ & 1.369 & 1.495 \\
\hline COB Aust ${ }^{d}$ & -.308 & .012 & $.735^{\star}$ & .717 & .753 & .421 & .021 & $1.524^{*}$ & 1.461 & 1.589 \\
\hline COB EngSpeak ${ }^{d}$ & -1.341 & .022 & $.262^{*}$ & .250 & .273 & .790 & .027 & $2.204^{*}$ & 2.091 & 2.324 \\
\hline
\end{tabular}

Source: CURF (ABS 2003c)

${ }^{a}$ Referent is 'spouse/partner'. ${ }^{b}$ Referent is 'remote'. ${ }^{\text {c }}$ Referent is 'not in the labour force'. ${ }^{d}$ Referent is 'Non English Speaking Background'.

* Significant at $<0.001$ level 
Table 5: Main source of assistance received by caregivers - 'no main source of assistance' is the reference category

\begin{tabular}{r|ll}
\hline & \multicolumn{1}{|c}{ Informal } & \multicolumn{1}{c}{ Formal } \\
\hline Age & Younger age cohorts & Younger age cohorts \\
Recipient of Care & Mental \\
Disability status & Profound & Profound \\
Primary carer & & \\
Age & Older age & Older age \\
Labour force status & Part time employment & In the labour force \\
Relationship to & Children, parents, other & Children, parents, other \\
recipient & & \\
Need & Unmet & Unmet \\
Duration of care & Decrease & Decrease \\
Country of birth & Non-English speaking & English speaking \\
Region & Major city, inner region & Major city, inner region \\
\hline
\end{tabular}

Source: Derived from the regression output presented in Table 4. 